\title{
The influence of location, socioeconomics, and behaviour on travel-demand by car in metropolitan university campuses
}

\author{
Julio A. Soria-Lara, Oriol Marquet, Carme Miralles-Guasch
}

\author{
A B S T R A C T
}

Metropolitan university campuses are unique places usually connected to cities and towns by motorised-transport infrastructures, originating an intense travel demand by car. This has triggered a growing concern about how policy action can be more effective to achieve sustainable mobility patterns. This paper aims to gain insight into how factors associated with what we term here as the "3Ss" approach (spatial location, socioeconomics and social behaviour) are influencing travel demand by car in the context of metropolitan university campuses. The daily mobility in the metropolitan Campus of the Autonomous University of Barcelona (UAB) in Greater Barcelona, Spain, provides the empirical focus. The obtained results explained the multifactorial origin of travel demand by car in the case study. First, it was seen how the age of the university mobile population and their weekly atten-dance at the UAB Campus were key factors in understanding the choice of taking a car in daily mobility. Second, statistical correlations were seen between car-weekly-km travelled by the university mobile population and factors such as gender, age, daily stay at the UAB Campus, and distance to the UAB Campus. The study also provides Autonomous University of Barcelona an excellent platform to reflect upon the elaboration of integrated transport policy packages.

Keywords: Sustainability Metropolitan areas Planning Policy

\section{Introduction}

The reduction in travel-demand by car in metropolitan regions is supposed to be a crucial issue with respect to achieving sustainability goals (e.g., Banister, 2005; Bertolini and Le Clercq, 2003; Newman and Kenworthy, 1999). The academic literature highlights, among others, the effects of metropolitan car-traffic on (i) Greenhouse gas (CHG) emissions. The transport sector and specifically car-traffic is a major source of GHG and has the fastest growth in $\mathrm{CO}_{2}$ emissions of any sector (e.g., Berrittella et al., 2008; Gilbert and Perl, 2010; Sperling and Gordon, 2009). (ii) Noise and environmental annoyance: Car trafficnoise is evidenced as the most important source of environmental annoyance (Ising and Kruppa, 2004). For example, a chronic exposure to severe annoyance by traffic-noise increases the health risk to the cardiovascular system and insomnia levels, as well as an increased risk of depression and respiratory health problems (e.g., Hong et al., 2010; Niemann et al., 
2006). (iii) Landscape fragmentation by car infrastructures: It consists of the loss of spatial connectivity of land uses, mainly affecting the natural habitats of animals and plants (Marulli and Mallarach, 2005), as well as the agricultural efficiency of such places (Aguilera et al., 2011). (iv) Social exclusion processes associated with car dependence: Severance of urban areas by car infrastructures has direct impacts on the quality of life of the population (Jones and Lucas, 2012; Sterrett et al., 2012). A crucial example is the development of processes associated with social exclusion due to certain urban areas becoming uniquely accessible by car (e.g., Lyons, 2003; Preston and Rajé, 2007;).

In the described context, metropolitan university campuses (MUCs) are seen as singular places, including people of different backgrounds, incomes, lifestyles and attitudes. They are strongly affected by metropolitan transport dynamics. Unlike urban campuses, MUCs tend to present horizontal connectivity with cities and towns based on motorised transport infrastructures (Balsas, 2003, p. 36). For this reason, most MUCs are highly car-oriented environments, generating strong environmental, societal and economic impacts. This has originated a growing body of theoretical and empirical studies during the last decades, mainly aimed at exploring the travel patterns associated with MUCs (e.g., Kerr et al., 2010; Limanond et al., 2011; Shannon et al., 2006; Tolley, 1996; Zhou, 2012).

In this sense, a more in-depth understanding of what factors are significantly affecting travel-demand by car in MUCs is highly relevant in order to design efficient transport policy packages (Miralles-Guasch and Domene, 2010). The "3Ss" approach is explored here as a potential solution. It hypothesises that travel-demand by car is affected by multiple causes, which can be mainly summarised in the following three categories: spatial location factors, socioeconomic factors and social behaviour factors. (i) Spatial location factors are associated with the spatial configuration of metropolitan regions and the location of MUCs (e.g., distance between municipalities and MUCs; abundance of public transport; urban density of municipalities). (ii) Socioeconomic factors are related to characteristics of the university mobile population, such as income levels and age. (iii) Social behaviour factors include the lifestyle of the university mobile population as a collective group (e.g., how long a period of time the university mobile population is undertaking daily travelling; how many days per week they are travelling). Since the origin of travel demand by car seems to be multifactorial in a generic context (Banister, 2005; Thøgersen, 2006), the "3Ss" approach establishes that gaining insight into the understanding of factors affecting the problem of car dependency in MUCs, from an integrated approach, could increment planning effectiveness, basically detecting target groups on the university mobile population which are highly susceptible to taking a car for daily mobility.

This paper aims at exploring the abovementioned discussion using the travel-demand by car originated by the Autonomous University of Barcelona (UAB) (located at the heart of the Barcelona Metropolitan Region, Spain), and compiled in a personal travel demand survey (TDS) disseminated in year 2013 among UAB members $(n=5935)$. In particular, the following research question is explored: How do factors related to spatial location, socioeconomics and social behaviour affect to the travel demand by car in the context of the metropolitan UAB Campus? We tried to answer the indicated research question in two phases. First, the question of which factors seemed to have more influence on the choice of taking (or not taking) a car in daily mobility was explored. To address this, a decision tree technique called CHi-squared Automatic Interaction Detection (CHAID) was used. Second, the correlation between car-weekly-km travelled by mobile population and the different factors from the "3Ss" approach (spatial location, socioeconomics and social behaviour) was analysed using nonparametric tests.

Section 2 describes the background of this study. The research method, including an in-depth description of the case study, is detailed in Section 3. Section 4 presents the main results of our research. In Section 5, the main findings are discussed. Finally, Section 6 is left for concluding remarks and recommendations for further research.

\section{University campuses and travel patterns}

Over the last decades a growing interest has emerged regarding the understanding of travel patterns linked to university campuses. While partial factors affecting university travel patterns have been previously analysed by several authors, limited attention has been paid to the study of this phenomenon from an integrated approach that simultaneously combines spatial location, socioeconomic and social behaviour factors. To contextualise the present research, the rest of this section will address specific details found in previous and relevant studies in the field.

In the context of the University of Idaho (U.S.A.), Delmelle and Delmelle (2012) explore the spatial and temporal patterns of student commuters in the small town of Moscow, home of the University of Idaho, with the intention of identifying measures to decrease car dependence among students. The authors show how variations in commuting choice seem to be more favoured by warmer months than by spatial location factors. In this sense, Shannon et al. (2006) also describe the results of an online survey that examined commuting patterns, potential for change and barriers and motivators affecting transport decisions at the Western Australia University campus. In this case, spatial location factors (e.g., distance to the campus) and socioeconomic factors (e.g., gender) were simultaneously used to demonstrate that the university was one of the most important trip generators in the area.

Socioeconomic factors were used by Duque et al. (2014) to analyse the campus community transportation profile. In particular, they study the environmental attitudes and behaviours of three campus commuter sub-groups (students, faculty, and non-professional staff), discussing the convenience of a set of transport measures that could increment the effectiveness of travel patterns associated with the university campuses such as more frequent bus schedules, 'free-rider' public bus passes, and dedicated city bike lanes. In this sense, Miralles-Guasch and Domene (2010) also study socioeconomic factors affecting travel patterns in the context of the Autonomous University metropolitan campus in Barcelona (Spain). The authors show 
how the public rail system is the main mode used for daily travelling to campus, and how the Autonomous University has a higher level of public transport use in comparison with the average public transport use in the wider context of the Metropolitan Area of Barcelona. Zhou (2012) also explores socioeconomic and car-sharing characteristics of those who commute to a university in Los Angeles (U.S.A.). The author demonstrates the relevance of age, gender and income in university car-sharing commuters.

From a behaviour viewpoint, Kerr et al. (2010) explore psychological factors influencing students' travel choices from the perspective of the Theory of Planned Behaviour. They specifically examine the car commuting behaviour of students from three different university campuses using a cross-sectional survey. The study reveals that behavioural intentions to travel by car were the strongest predictors of car commuting behaviour, while no relationship was found between habits and intentions.

Finally, an integrated approach is used by Limanond et al. (2011) to analyse travel behaviour patterns in a rural university in Thailand. To address this, the authors compare spatial location factors (e.g., daily distance travelled by transport mode), socioeconomic factors (e.g., gender), and behavioural factors (e.g., car availability). The study shows how the high social interdependency among university members (fundamentally students) causes complex travel behaviour patterns. It is specifically seen how those students who do not own a vehicle did not choose travelling by bus as their first choice, but they tended to rely more on riding with a friend to travel to various places ( $40-50 \%$ of all trips).

\section{Research method}

\subsection{Case study}

UAB is located in a suburban area in Greater Barcelona (Fig. 1), a region that covers an area of $3242 \mathrm{~km}^{2}$, with approximately 5 million inhabitants and 164 municipalities. Greater Barcelona is made up of two metropolitan belts that extend from the city outwards. The first belt has both a high residential density and a high land use diversity. However, the second belt is characterised by low residential density and a poor abundance of public transport systems (Miralles-Guasch et al., 2014). The UAB campus is located some $15 \mathrm{~km}$ from the city centre and shares some urban characteristics of the second metropolitan belt (e.g., low urban densities and scattered urban development). It is situated at the intersection between two major motorways. Parking at the UAB Campus is free-for-all. Despite its suburban setting, it is noteworthy that the UAB Campus has a high public transport accessibility, with three train stations having direct connections to Barcelona city and other surrounding cities (e.g., Sabadell and Terrassa), as well as several metropolitan bus stations.

The UAB community consists of approximately 47,866 members (86.2\% students, $8.6 \%$ teaching/research staff and $5.2 \%$ others, including administrative staff). As a consequence of its suburban location, most of the UAB members are living in the surrounding municipalities. With a quarter of all residences, Barcelona has the highest concentration of UAB members

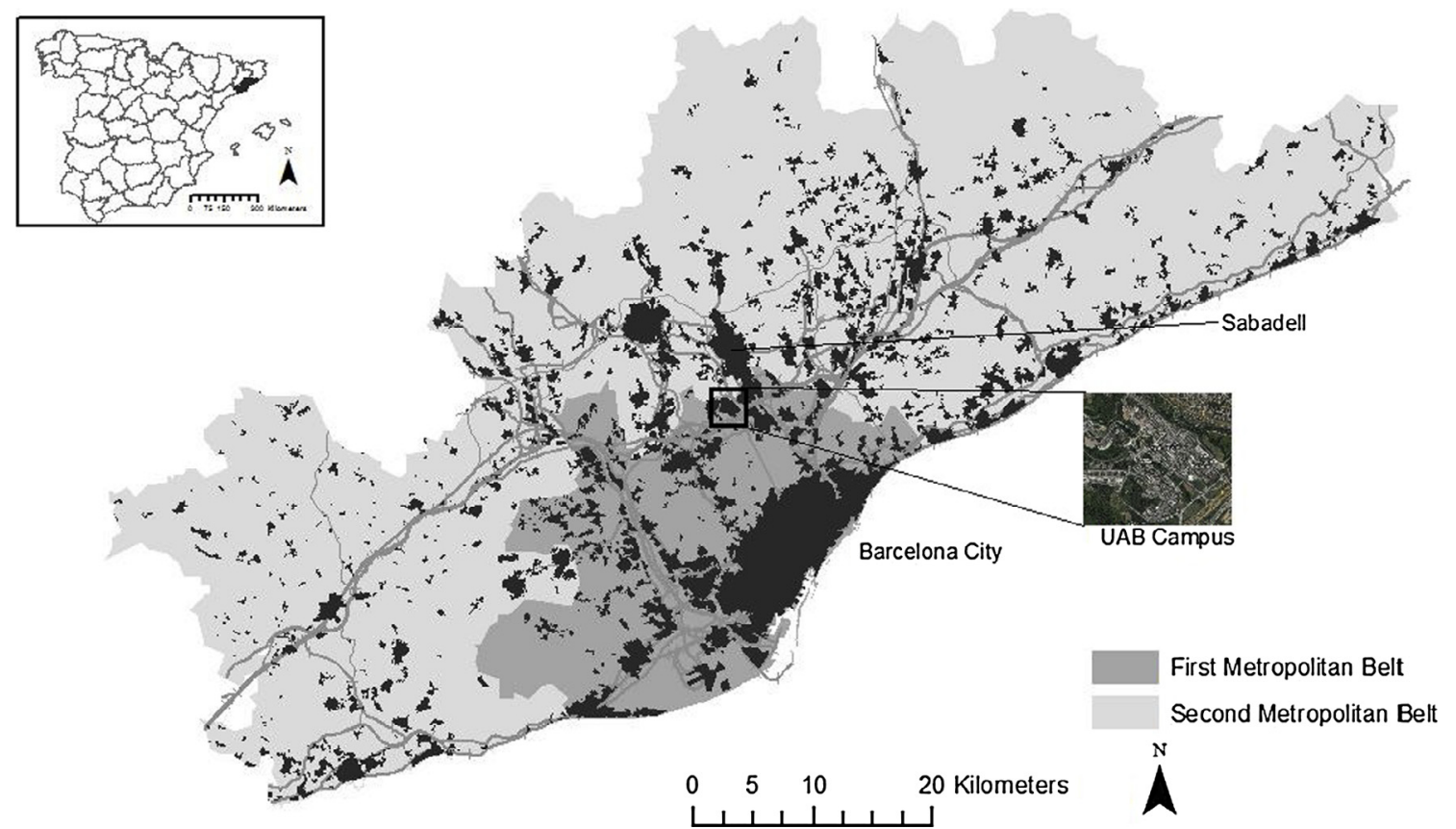

Fig. 1. Location of UAB Campus in Greater Barcelona. 
Table 1

Selected factors according to the "3Ss" approach.

\begin{tabular}{|c|c|c|c|c|c|}
\hline \multicolumn{6}{|c|}{ The "3Ss" approach from the daily mobility survey $(N=5935)$} \\
\hline \multicolumn{2}{|l|}{ Spatial location } & \multicolumn{2}{|c|}{ Socioeconomics } & \multicolumn{2}{|c|}{ Social behaviour } \\
\hline Factors & $n(\%)$ & Factors & $n(\%)$ & Factors & $n(\%)$ \\
\hline \multicolumn{2}{|c|}{ Urban density (pop $\left./ \mathrm{km}^{2}\right)$} & \multicolumn{2}{|l|}{ Gender } & \multicolumn{2}{|c|}{ Car availability } \\
\hline$<5000$ & $3220(54.21)$ & Men & $2132(35.92)$ & Yes & $3061(51.57)$ \\
\hline $5000-10,000$ & $823(13.86)$ & Women & $3803(64.07)$ & Not & $2874(48.42)$ \\
\hline$>10,000$ & $1892(31.87)$ & & & & \\
\hline \multicolumn{2}{|c|}{ Trip distance $(\mathrm{km})$} & \multicolumn{2}{|l|}{ Age (years) } & \multicolumn{2}{|c|}{ Attendance at $U A B$} \\
\hline$<7.5$ & $1689(28.45)$ & $18-29$ & 3424 (57.69) & 1 day & $137(2.30)$ \\
\hline $7.5-15$ & $717(12.08)$ & $30-55$ & $1815(30.58)$ & 2 days & $231(3.89)$ \\
\hline $15-30$ & $2562(43.16)$ & $>55$ & $696(11.72)$ & 3 days & $396(6.67)$ \\
\hline \multirow[t]{2}{*}{$>30$} & $967(16.29)$ & & & 4 days & $1079(18.18)$ \\
\hline & & & & $>5$ days & $4092(68.94)$ \\
\hline \multicolumn{2}{|c|}{ Public transport accessibility (number of transfers) } & \multicolumn{2}{|l|}{ Role at $U A B$} & \multicolumn{2}{|c|}{ Daily stay at $U A B$} \\
\hline Direct & $2041(34.38)$ & Students & $3537(59.59)$ & $<4 \mathrm{~h}$ & 1309 (22.05) \\
\hline 1 & $817(13.76)$ & Staff & $2398(40.41)$ & $4-8 \mathrm{~h}$ & $2408(40,57)$ \\
\hline 2 & $1.623(27.34)$ & & & $>8 \mathrm{~h}$ & $2218(37.37)$ \\
\hline$>2$ & $1454(24.49)$ & & & & \\
\hline \multicolumn{6}{|c|}{ Settlement size (hab.) } \\
\hline$<5000$ & $315(5.31)$ & & & & \\
\hline $5000-20,000$ & $825(13.91)$ & & & & \\
\hline $20,000-50,000$ & $540(9.07)$ & & & & \\
\hline$>50,000$ & 4255 (71.69) & & & & \\
\hline
\end{tabular}

(25.7\%). The percentages for other major municipalities are as follows: Sabadell (10.5\%), Cerdanyola del Vallès (9.3\%), Terrassa (6.3\%) and Sant Cugat del Vallès (3.8\%). Unlike U.S.A. university campus mentioned during Section 2, UAB Campus mainly focuses on teaching and research activities, and there is only a limited accommodation on the Campus for students and visiting lecturers. Furthermore, it is worth to mentioning that there is a very good connection by public transport modes (fundamentally by train).

\subsection{Data gathering}

In 2013 the UAB community was asked to participate in an Online (Internet-based) personal, travel-demand survey. The survey was hosted in the University Intranet and was available to be answered online for the whole university community for several weeks. An informative banner was set up on the University Webpage to encourage participation. In total, 5935 respondents filled out the form, resulting in a marginal error of $\pm 1.29 \%$. Results were weighted according to distribution by gender and role at the university, in order to balance the sample with respect to the universe of study. This travel demand survey has been carried out six times since year 2001. It provides valuable information, not only because it is a faithful reflection of movement patterns in a unique area such as the UAB campus, but also because it makes it possible to follow data trends throughout a 13-year timeline. ${ }^{1}$ The survey was structured in four main blocks: (i) general sociodemographic questions, such as age, gender and car availability; (ii) daily mobility habits, such as number of trips or number of hours at the UAB; (iii) usual transport modes and modal choice; and (iv) other questions. For the evaluation of the received enquiries, respondents were required to provide details about their professional activity, such as residential location and role at the university (student, academic staff, administrative staff).

Following the design of the survey, a total of 10 factors were selected and grouped according to the "3Ss" approach. In this way, the selected spatial location factors were (i) trip distance; (ii) public transport accessibility to UAB; (iii) urban density; and (iv) settlement size. The socioeconomic factors included (i) gender; (ii) age; and (iii) role at UAB. The selected social behaviour factors were (i) car availability; (ii) weekly attendance at the UAB campus; and (iii) daily stay at UAB (Table 1).

\subsection{Statistical analysis}

To address the research question presented in the introduction of the paper, two complementary statistical analyses were conducted. First, a decision tree technique called CHi-squared Automatic Interaction Detection (CHAID) was used. It permitted us to rank what factors of the "3Ss" approach were more influential on the choice of taking car or do not take it in daily mobility to UAB Campus. Second, the nonparametric Mann-Whitney $U$ test ( $U$ test) was used to correlate car-weekly-km

\footnotetext{
${ }^{1}$ More information about the survey in Spanish and Catalan can be found here: http://www.uab.cat/web/la-mobilitat-a-la-uab/enquesta-de-mobilitat1255501888126.html.
} 
travelled by the mobile population and each studied factor of the "3Ss" approach, providing a more in-depth understanding about the phenomenon of travel-demand by car in the case study. In the remainder of this section we will detail these two methodological choices.

The first part of the analysis was based on detection of strategic decisions on taking a car (or not taking it) using decision trees. They are commonly used in decision analysis, helping to identify the most likely strategy to reach a goal. Over the last year, decision trees have been increasingly used in transport studies as a useful method to assess the hierarchy of factors affecting a specific modal choice (e.g., Pitombo et al., 2011; Marquet and Miralles-Guasch, 2014; Zhang et al., 2014). Essentially, a decision tree is a decision support tool that uses a tree-like graph or model of decisions and their possible consequences. CHAID is one of the most popular methods used in science and business for performing classification or segmentation in making choices. It uses the given data to automatically build a series of "if-then" rules (in the form of a decision tree) that can classify the sample with higher accuracy than when using traditional exploratory statistical methods. In particular, the CHAID method was selected due to the fact that it is a nonparametric decision tree. In our specific study the dependent variable was the choice of taking a car in daily commuting to/from the UAB Campus, while the independent variables were the set of factors identified for the application of the "3Ss" approach. The CHAID model was implemented using IBM SPSS 19 software.

The second part of the analysis was based on correlating car-weekly-km travelled by the university mobile population and each studied factor from the "3Ss" approach (see Section 2.2). This permitted to obtain detailed information about significant factors affecting travel demand by car in the study case. To do that, the $U$ test was used. It is a nonparametric test of the null hypothesis that two populations are the same against an alternative hypothesis, especially, that one particular population tends to have larger values than the other. The test involves the calculation of a statistic, termed $U$, whose distribution under the null hypothesis is known. Significant differences on car-weekly-km travelled by mobile population at a statistical significance $\mathrm{p}=0.05$ for the potential options of each studied factors would indicate a strong influence of the factor on travel-demand by car and vice versa. The dependent variable car-weekly-km travelled by the mobile population is presented in Section 3 as the interval of $\mathrm{km}$ formed by the 25 th and 75 th percentiles (50\% of representative car-weekly-km).

\section{Results}

\subsection{Results of CHAID analysis}

A single decision tree was built, combining the total of selected factors from the "3Ss" approach (Fig. 2). The specific aim of the decision tree was to identify and rank what factors were directly affecting the choice of taking car or do not take it in everyday mobility (see node 0 in Fig. 2). Within the socioeconomics group of factors, age seemed to be the most relevant in the choice of taking car for daily travelling to UAB Campus (see nodes 1, 2 and 3). In particular, the group of mobile population in the range 18-29 years of age had the lowest car-use rates (25.4\%); however, the mentioned rates were higher between the mobile population older than 30 years of age (56.4\% in population between 30 and 54 years of age; $64.1 \%$ in population higher than 55 years of age). This permitted to identify two main profiles of car users within the mobile population: (i) mobile population between 18 and 29 years of age, whose car-use rates were $<50 \%$; and (ii) mobile population older than 30 years of age who preferred to take a car in their daily mobility to UAB Campus (car-use rates $>50 \%$ ).

The decision tree provided additional information on the two cited profiles of mobile population. Focusing on the first profile: mobile population between 18 and 29 years of age, whose car-use rates were $<50 \%$, four new sub-groups of mobile population were found. First, the mobile population who arrived to the UAB Campus between 9 and 12 am (node 4) and lived at distances from the UAB Campus of less than $7.5 \mathrm{~km}$ or more than $30 \mathrm{~km}$ (node 8); this sub-group of population experienced the lowest rates of car-use (19.3\%). Second, the mobile population arriving to the UAB Campus between 9 and $12 \mathrm{am}$ (node 4) and living at distances from the UAB Campus between $7.5 \mathrm{~km}$ and $30 \mathrm{~km}$ (node 9); in this sub-group, the rate of car-use was $29.6 \%$. The third identified sub-group was formed by the mobile population arriving to the UAB Campus before 9 am or later than midday (node 5), as well as attending the UAB Campus for 3 or more days per week (node 10). The choice of taking car in this subgroup was made by the $28.4 \%$ of the mobile population. Finally, the fourth and last subgroup identified was formed by the mobile population arriving to the UAB Campus before 9 am or later than mid-day (node 5), as well as attending the UAB Campus for a maximum of 1 or 2 days per week (node 11), and $45.7 \%$ of the mobile population in this subgroup took a car for daily travelling to the UAB Campus.

Focusing on the second identified profile of the mobile population: older than 30 years of age who had a preference for taking a car for daily travelling to the UAB Campus, additional information was obtained by the CHAID method. In particular, it was seen that the car-uses-rates had variations depending on whether the mobile population older than 44 years of age (node 3) attended the UAB Campus for less than 4 days per week (node 6) or 5 days and more per week (node 7). While caruse-rates were $56.4 \%$ in the first cited subgroup, such rates rose to $67.2 \%$ when this profile of mobile population attended the UAB Campus 5 days or more per week.

\subsection{Results of $U$ test}

The group of factors related to spatial location was the first to be analysed (Table 2 and Fig. 3). Unlike the rest of the groups of factors (socioeconomics and social behaviour), significant differences at a statistically significant level $p=0.05$ 


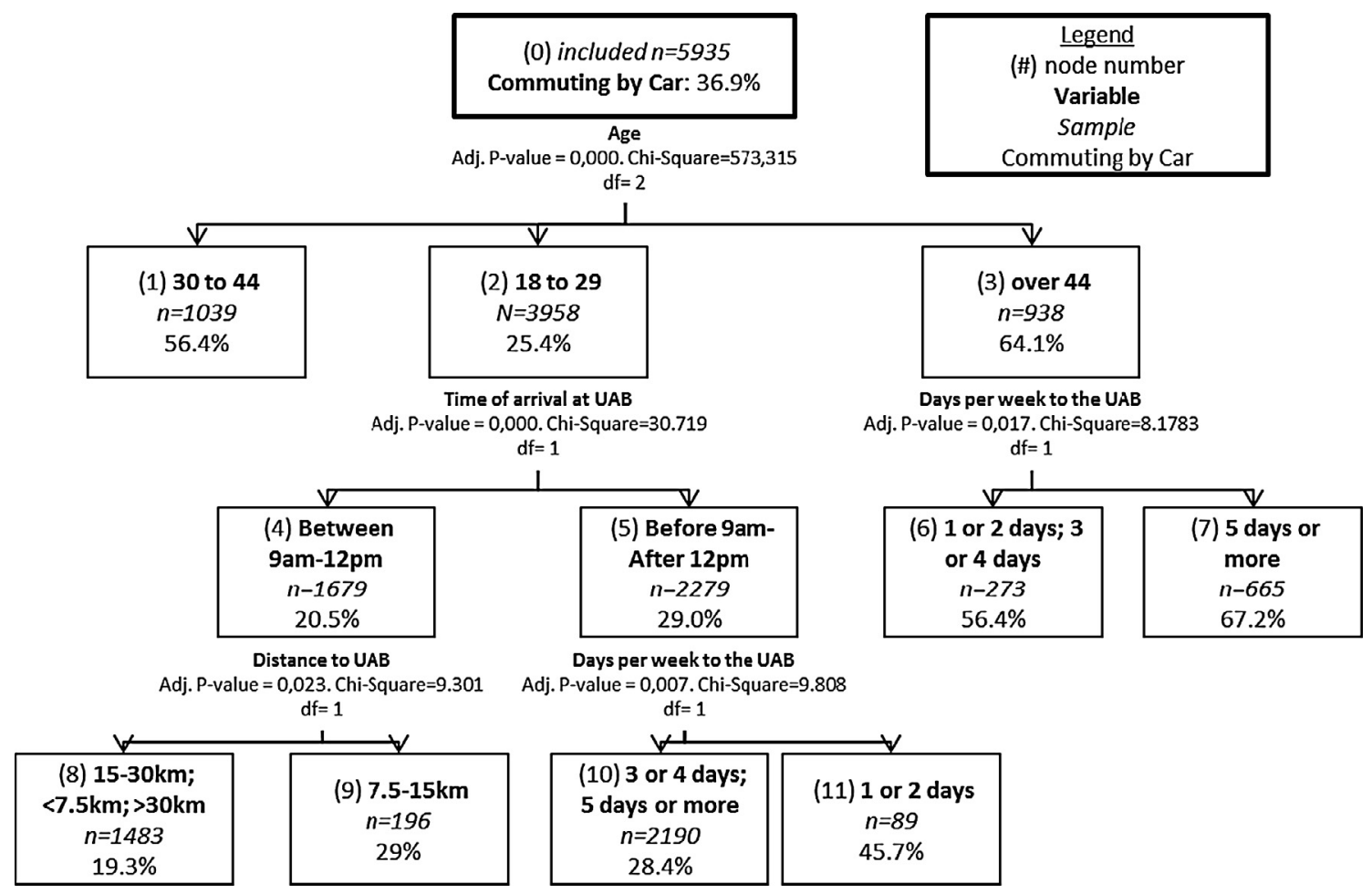

Fig. 2. Decision tree ranking factors affecting the choice of taking car for daily travelling to the UAB Campus.

were not found on car-weekly-km travel by the mobile population for the total of factors studied within the group of spatial location. In particular, no statistical differences on car-weekly-km travelled by mobile population were found in the case of settlement size. This meant that settlement size was not a relevant factor to explain car-weekly-km travelled by mobile population in the study case.

For the rest of the factors included into the group of spatial location (urban density, public transport accessibility and trip distance), the $U$ test showed significant differences at significance $\mathrm{p}=0.05$. This meant that such factors seemed to have influence on car-weekly-km travel by the mobile population. In the case of urban density, the $U$ test showed statistical differences on car-weekly-km travel between the mobile population who lived in urban densities $>10,000 \mathrm{pop} / \mathrm{km}^{2}$ (e.g., Barcelona, Sabadell and Terrassa) and car-weekly-km travel by the mobile population living in municipalities with lower values of urban densities, while $50 \%$ of the car-weekly-km travelled by the mobile population who lived in urban densities higher than $10,000 \mathrm{pop} / \mathrm{km}^{2}$ was estimated to be between 0 and $104,4 \mathrm{~km}$, which is the total $50 \%$ of the car-weekly-km travelled by the mobile population living in urban densities lower than 10,000 pop/hab ranging from 0 to $37 \mathrm{~km}$. This showed that living in municipalities with the highest urban densities was affected in a significant way with respect to travelling more carweekly-km in the case study. This result is due to the majority of UAB members (25.7\%) are living in the city of Barcelona, which is the municipality with higher urban densities, as well as the city located farther away from the university Campus.

Public transport accessibility was another factor studied within the group of spatial location. The $U$ test found significant differences on car-weekly-km travelled by the mobile population living in municipalities with direct connection to the UAB Campus (50\% of car-weekly-km travelled ranged from 0 to $100.2 \mathrm{~km}$ ) and the mobile population in municipalities with 1 public transport transfer to the UAB Campus (50\% of car-weekly-km travelled ranged from 0 to $36.5 \mathrm{~km}$ ), plus, between car-weekly-km travelled by the mobile population living in municipalities with one public transport transfer to the UAB Campus and the mobile population in municipalities with more than 2 public transport transfers ( $50 \%$ of car-weekly-km travelled ranged from 0 to $90.5 \mathrm{~km}$ ). Finally, the last factor analysed within the spatial location group was the distance to $U A B$ Campus. Here, the $U$ test showed statistical differences between car-weekly-km travelled by the mobile population living at a distance lesser than $7.5 \mathrm{~km}$ ( $50 \%$ of car-weekly-km travelled ranged from 0 to $21 \mathrm{~km}$ ) to the UAB Campus and the rest of considered distances ( $50 \%$ of car-weekly-km travelled ranged from 0 to a maximum of $104.4 \mathrm{~km}$ ).

The group of factors related to socioeconomics was the second to be studied (Table 2 and Fig. 4). In the case of gender, the $U$ test found statistical differences between men and women $(\mathrm{p}=0.05)$. In the case of men, $50 \%$ of car-weekly-km travelled was estimated between $0 \mathrm{~km}$ and $62.85 \mathrm{~km}$. However, this value was lower in the case of women (50\% of car-weekly-km travelled ranged from 0 to maximum of $40.5 \mathrm{~km}$ ). There are no specific explanations to this result. Probably, individual preferences are affecting significantly the higher use of cars by men than women. The age people was another socioeconomic factor where the $U$ test found statistical differences $(p=0.05)$ between the total group of ages studied (18-29 years of 
Table 2

Statistical analysis (Mann-Whitney $U$ test).

Spatial location factors

Urban density (pop $/ \mathrm{km}^{2}$ )

$\begin{array}{llll}<5000 & <5000 & 5000-10,000 & >10,000 \\ 5000-10,000 & 0.1951 & & \\ >10,000 & 0.0059^{*} & 0.0001^{*}\end{array}$

Trip distance $(\mathrm{km})$

$\begin{array}{ll}<7.5 & <7.5 \\ 7.5-15 & \\ 15-30 & 2.24 \mathrm{E}-09 \\ >30 & 3.69 \mathrm{E}-13 \\ & 4.19 \mathrm{E}-05\end{array}$

$7.5-15$

$15-30$

$>30$

$$
>30
$$

0.01868

0.272

0.0578

Public transport accessibility (number of transfers)

$\begin{array}{ll}\text { Direct } & \text { Direct } \\ 1 & \\ 2 & 0.0432 \\ >2 & 1.0000 \\ & 1.0000\end{array}$

$\begin{array}{ll}0.975 & 1 \\ 1 & 1\end{array}$

Socioeconomic factors

Gender

$5000-20,000$
$20,000-50,000$
$>50,000$

$<5000$

Men

$0.0001^{*}$

Age (years)

Men

Women

$18-29$

$2.79 \mathrm{E}-83^{*}$

$5.09 \mathrm{E}-67^{*}$

Students

$1.23 \mathrm{E}-74^{*}$

Students

Staff

Social behaviour factors

Car availability

Yes

Not

Attendance at UAB

$\begin{array}{ll}1 \text { day } & 1 \text { day } \\ 2 \text { days } & \\ 3 \text { days } & 0.4162 \\ 4 \text { days } & 0.294 \\ >5 \text { days } & 1 \\ & 0.5747\end{array}$

Daily stay at UAB

$<4 \mathrm{~h}$

$4-8 \mathrm{~h}$

$>8 \mathrm{~h}$
Yes

$0^{*}$

$<4 \mathrm{~h}$

$9.56 \mathrm{E}-05^{*}$

$2.18 \mathrm{E}-14^{*}$
Not

$\begin{array}{lll}2 \text { days } & 3 \text { days } & 4 \text { days } \\ 1 & \\ 0.6847 & 0.002158^{*} & \\ 1 & 1 & 7.66 \mathrm{E}-09^{*} \\ 4-8 \mathrm{~h} & >8 \mathrm{~h} & \\ 2.13 \mathrm{E}-05^{*} & \end{array}$

1

0.0940

0.0052

$5000-20,000$

1

2

1.0000

$20,000-50,000 \quad>50,000$

1

$>55$

0.01121

Staff

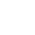



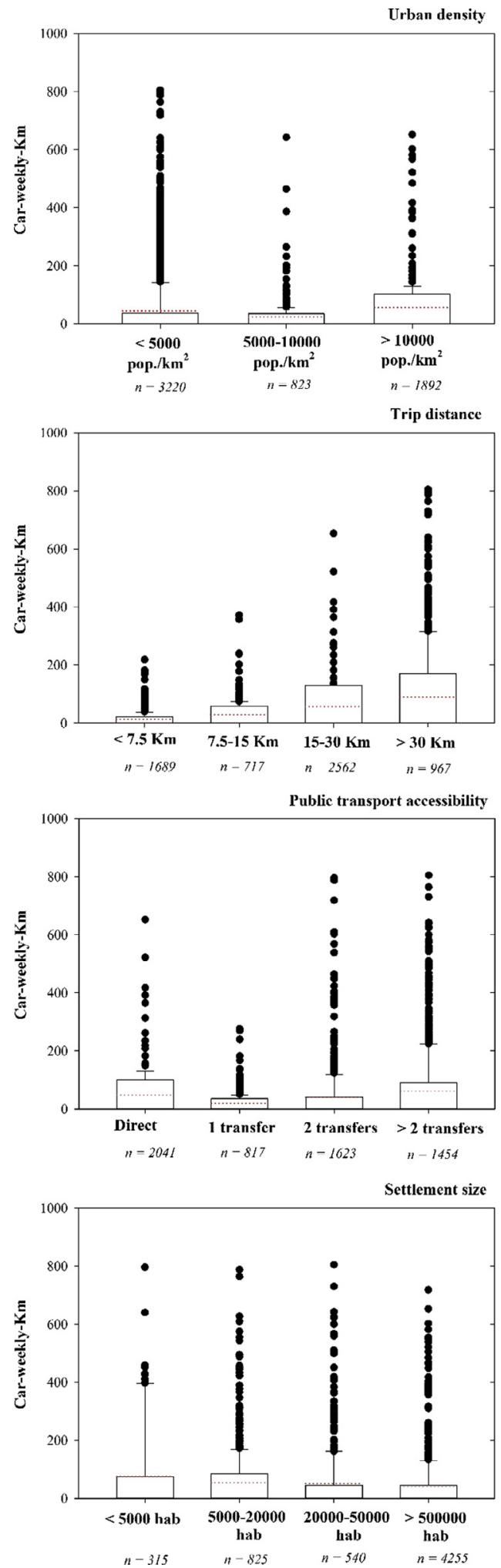

Fig. 3. Car-weekly-km travelled and spatial location factors (Legend: Points are outliers (>percentile 90th); Upper-part of box plot is 75th percentile; Lowerpart of box plot is 25th percentile; Dashed line is the median). 

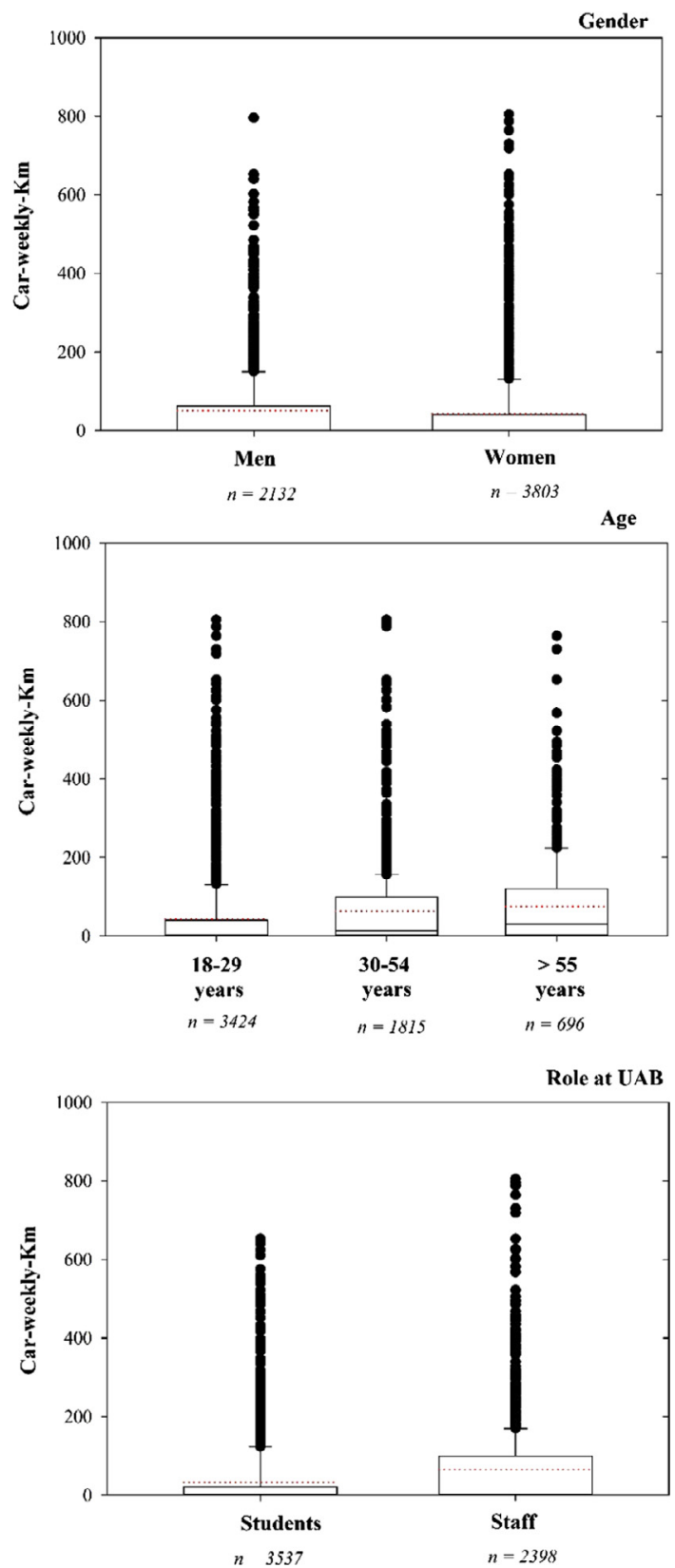

Fig. 4. Car-weekly-km travelled and socioeconomic factors (Legend: Points are outliers (>90th percentile); Upper part of box plot is 75 th percentile; Lower part of box plot is 25th percentile; Dashed line is the median).

car-weekly-km travelled ranged from 0 to a maximum of $21.6 \mathrm{~km}$ ). Income levels can explain the previous results among other factors. While people older than 55 years of age can assume more easily the cost associated with car use, students and young people would have more difficulties to do that. Furthermore, accommodation facilities in the UAB Campus are mainly used by students, which could affect the lower values of car-weekly-km estimated for younger people.

Lastly, the group of factors associated with social behaviour was the third to be analysed (Table 2 and Fig. 5). Within this group, the $U$ test showed statistical differences $(\mathrm{p}=0.05)$ for the factor car availability. In this sense, the mobile population with daily access to a car for travelling to the UAB Campus travelled more car-weekly-km (50\% of car-weekly-km travelled ranged from 0 to maximum of $130.5 \mathrm{~km}$ ) than the mobile population without daily car access ( $50 \%$ of car-weekly-km travelled was estimated at between 0 and $22.3 \mathrm{~km}$ ). In the case of weekly attendance at UAB Campus, the analysis revealed statistical differences $(p=0.05)$ between the mobile population attending the UAB Campus for 5 days or more $(50 \%$ of carweekly-km travelled was estimated at between 0 and $74.2 \mathrm{~km}$ ) and the rest of the mobile population (50\% of car-weekly- 

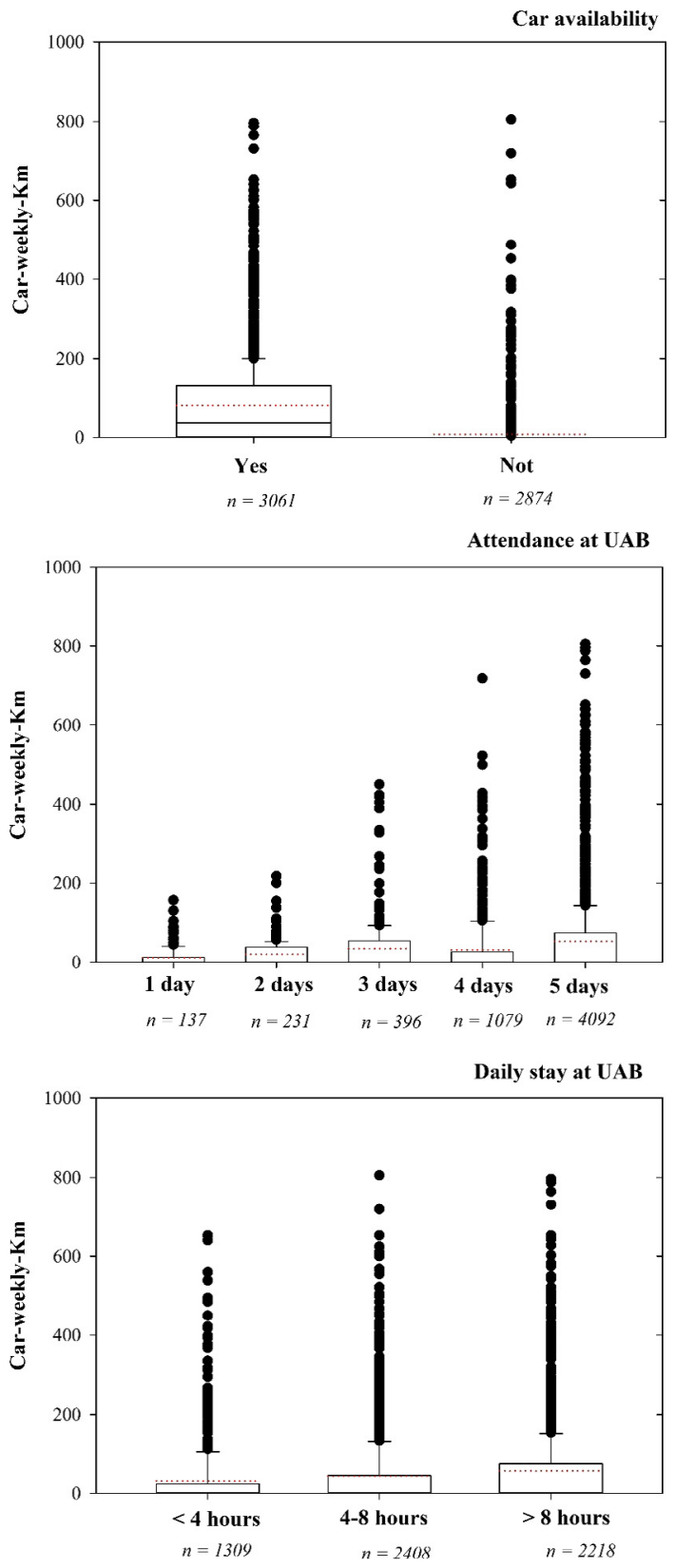

Fig. 5. Car-weekly-km travelled and social behaviour factors (Legend: Points are outliers (>percentile 90th); Upper-part of box plot is percentile 75th; Down-part of box plot is percentile 25th; Dashed line is the median).

$\mathrm{km}$ travelled ranged from 0 to maximum of $54.6 \mathrm{~km}$ ). Finally, the last studied factor within this group was daily stay at $U A B$ Campus. The $U$ test found statistical differences $(\mathrm{p}=0.05)$ between the three study options $(<4 \mathrm{~h}$ per day; $4-8 \mathrm{~h}$ per day; $>8 \mathrm{~h}$ per day). The mobile population staying at the UAB Campus more than $8 \mathrm{~h}$, travelled more car-weekly-km $(50 \%$ of carweekly-km travelled ranged from 0 to maximum of $120.12 \mathrm{~km}$ ) than the rest of the mobile population $(50 \%$ of carweekly-km travelled ranged from 0 to maximum of $75.5 \mathrm{~km}$ ). The cost of car use could be related to the previous result. While staying more than $8 \mathrm{~h}$ at UAB Campus could compensate the higher cost of using car, for short-time travels it is cheaper to use public transport, including the money savings linked to parking facilities.

\section{Discussion}

As hypothesised at the beginning of this article, travel demand by car is likely to be influenced by many, and different, causes in our case study. Unlike partial approaches to the understanding of travel-demand by car in both a wider context 
(Bhat and Guo, 2007; Ewing and Cervero, 2010; Oakes et al., 2007; Soria-Lara et al., 2015) and the specific case of university campuses (e.g., Limanond et al., 2011; Kerr et al., 2010; Shannon et al., 2006), the application of the "3Ss" approach has evidenced that factors related to spatial location, socioeconomics and social behaviour are simultaneously affecting travel demand by car, resulting in a novel approach.

Results from both the CHAID model and the $U$ test have evidenced that spatial location factors have less influence than socioeconomic and social behaviour factors in explaining the choice of using a car as the main mode of transport to get in and out of the UAB campus. A similar conclusion was reached by Delmelle and Delmelle (2012), demonstrating that spatial location factors seemed to be less relevant for explaining university travel patterns than other factors such as the climatic conditions and the cost of university parking. Overall, the socioeconomic factors are the most determinant with respect to the use of the car in the context of the UAB Campus, while social behaviour variables followed next. These results confirm the findings obtained by Miralles-Guasch and Domene (2010), Shannon et al. (2006), who evidenced the importance of the role in the campus (e.g., students, staff) to understand the travel patterns associated with daily mobility in those places. Furthermore, the results in this study show how age (fundamentally people $>55$ ), gender (fundamentally men) and low-income people can explain a fundamental part of the reasons associated with travel demand by car in a university campus, as also was evidenced by Zhou (2012) in the case of Los Angeles (U.S.A.).

Accordingly, mapping the profile of car-dependent population at the UAB Campus provides local-planners and institutions (both the UAB administration and the Catalan government) with an excellent platform to increase the effectiveness of transport policy packages on travel demand by car. Although the UAB campus has strong connections by train to the closest metropolitan cities, transport policy packages adopted by these institutions have not yet had clear targets, reducing their effectiveness on automobile dependence (Miralles-Guasch and Domene, 2010). The described situation has been also evidenced in other university campuses across the world. For example, in the context of several metropolitan university campuses in U.S.A., Duque et al. (2014) showed how the existing university transportation policies aimed at promoting more pedestrian traffic on campus, providing more local and on-campus shuttle services. However, those policies did not impact the particular segment of the university contributing the most to its carbon footprint from transportation activity: nonprofessional staff. In this respect, Kerr et al. (2010) also indicated that initiatives to alter car commuting behaviour should target individuals' car commuting intentions, aiming to weaken these or to strengthen intentions to use other modes of transport. In the particular case of the UAB campus, the obtained results have demonstrated how transport policies should be mainly aimed at men who are older than 55 years and who live at a distance to the UAB campus of lesser than $7.5 \mathrm{~km}$ or more than $30 \mathrm{~km}$ and who attended the UAB campus five days or more per week. However, a slight improvement on traveldemand by car could be achieved if transport policy packages were focused on women who are younger than 29 years old and who live within a distance to the UAB Campus of between $7.5 \mathrm{~km}$ and $30 \mathrm{~km}$ and who attend the UAB campus less than 4 days per week.

\section{Conclusions}

We can now answer the research question posed at the beginning of this paper How do factors related to Spatial location, Socioeconomics and Social behaviour (the "3Ss" approach) affect the travel demand by car in the context of the metropolitan UAB Campus? The potential answers were explored within the particular context of the daily mobility of the UAB Campus (Greater Barcelona, Spain), by asking UAB members to fill in a personal travel-demand survey. On the one hand, using the CHAID method aided the study of how factors associated with "the 3Ss approach" were influenced on the choice of taking car by mobile population in its daily mobility to the UAB Campus or do not take it. On the other hand, the $U$ test was used to correlate factors included in "the 3Ss approach" and car-weekly-km travelled by the mobile population in the case study. The obtained results revealed two interesting and complementary tiers of findings: (i) the multifactorial origin of travel-demand by car was evidenced; (ii) an excellent platform to increase the effectiveness of policy action, establishing specific targets of vulnerable university population to the daily use of private automobiles.

Our analysis was based upon both the choice of using a car in daily mobility for travel to and from the UAB Campus and the car-weekly-km travelled by university mobile population. The exploration of variables related to spatial location, socioeconomics and social behaviour seemed to be a novel approach in the study of university travel patterns, covering not only built environment or economic factors, but also some socio-psychological aspects that were expressed through measureable lifestyle habits. In particular highlighted was the incorporation of social behaviour variables, such as daily attendance at UAB or the time spent daily on the UAB Campus, fundamentally, when only limited attention is paid to such social behaviour factors in recent modal choice analysis.

Finally, new research lines have been opened by the undertaking of this research; for example, the exploration of the effectiveness of transport policy packages on university mobile population profiles, as well as the study of tendencies over the year on factors affecting the travel-demand by car in the case study.

\section{Acknowledgements}

This research was carried out whithin the framework of the following research project: Movilidad cotidiana activa y saludable en entornos urbanos de proximidad. enfoques multimetodologicos: tracking living labs, encuestas de movilidad 


\section{y estudios cualitativos funded by Ministerio de Economía y Competitividad, Subdirección General de Proyectos de Investi- gación (Ref: CSO2016-74904-R).}

\section{References}

Aguilera, F., Valenzuela, L.M., Botequilha-Leitão, A., 2011. Landscape metrics in the analysis of urban land use patterns: a case study in a Spanish metropolitan area. Landscape Urban Plann. 99 (3), 226-238.

Balsas, C.J., 2003. Sustainable transportation planning on college campuses. Transp. Policy 10 (1), 35-49.

Banister, D., 2005. Unsustainable Transport: City Transport in the New Century. Taylor \& Francis.

Berrittella, M., Certa, A., Enea, M., Zito, P., 2008. Transport policy and climate change: how to decide when experts disagree. Environ. Sci. Policy 11 (4), 307314.

Bertolini, L., Le Clercq, F., 2003. Urban development without more mobility by car? Lessons from Amsterdam, a multimodal urban region. Environ. Plann. A 35 (4), 575-590.

Bhat, C.R., Guo, J.Y., 2007. A comprehensive analysis of built environment characteristics on household residential choice and auto ownership levels. Transp. Res. Part B: Methodol. 41 (5), 506-526.

Delmelle, E.M., Delmelle, E.C., 2012. Exploring spatio-temporal commuting patterns in a university environment. Transp. Policy 21, 1-9.

Duque, R.B., Gray, D., Harrison, M., Davey, E., 2014. Invisible commuters: assessing a university's eco-friendly transportation policies and commuting behaviours. J. Transp. Geogr. 38, 122-136.

Ewing, R., Cervero, R., 2010. Travel and built environment. J. Am. Plann. Assoc. 76 (3), 265-294.

Gilbert, R., Perl, A., 2010. Transportation in the post-carbon world. Post Carbon Reader, 347-360.

Hong, J., Kim, J., Lim, C., Kim, K., Lee, S., 2010. The effects of long-term exposure to railway and road traffic noise on subjective sleep disturbance. J. Acoust. Soc. Am. 128 (5), 2829-2835.

Ising 1, H., Kruppa, B., 2004. Health effects caused by noise: evidence in the literature from the past 25 years. Noise Health 6 (22), 5.

Jones, P., Lucas, K., 2012. The social consequences of transport decision-making: clarifying concepts, synthesising knowledge and assessing implications. J. Transp. Geogr. 21, 4-16.

Kerr, A., Lennon, A., Watson, B., 2010. The call of the road: factors predicting students' car travelling intentions and behaviour. Transportation 37 (1), 1-13.

Limanond, T., Butsingkorn, T., Chermkhunthod, C., 2011. Travel behavior of university students who live on campus: a case study of a rural university in Asia. Transp. Policy 18 (1), 163-171.

Lyons, G., 2003. The introduction of social exclusion into the field of travel behaviour. Transp. Policy 10 (4), $339-342$.

Marquet, O., Miralles-Guasch, C., 2014. Walking short distances. The socioeconomic drivers for the use of proximity in everyday mobility in Barcelona. Transp. Res. Part A: Policy Pract. 70, 210-222.

Marulli, J., Mallarach, J.M., 2005. A GIS methodology for assessing ecological connectivity: application to the Barcelona Metropolitan Area. Landscape Urban Plann. 71 (2), 243-262.

Miralles-Guasch, C., Domene, E., 2010. Sustainable transport challenges in a suburban university: the case of the Autonomous University of Barcelona. Transp. Policy 17 (6), 454-463.

Miralles-Guasch, C., Martínez Melo, M., Marquet Sarda, O., 2014. On user perception of private transport in Barcelona Metropolitan area: an experience in an academic suburban space. J. Transp. Geogr. 36, 24-31.

Newman, P., Kenworthy, J., 1999. Sustainability and Cities: Overcoming Automobile Dependence. Island Press.

Niemann, H., Bonnefoy, X., Braubach, M., Hecht, K., Maschke, C., Rodrigues, C., Robbel, N., 2006. Noise-induced annoyance and morbidity results from the pan-European LARES study. Noise Health 8 (31), 63.

Oakes, J.M., Forsyth, A., Schmitz, K.A., 2007. The effects of neighborhood density and street connectivity on walking behavior: the Twin Cities walking study. Epidemiol. Perspect. Innov. 4 (16), 113-224.

Pitombo, C.S., Kawamoto, E., Sousa, A.J., 2011. An exploratory analysis of relationships between socioeconomic, land use, activity participation variables and travel patterns. Transp. Policy 18 (2), 347-357.

Preston, J., Rajé, F., 2007. Accessibility, mobility and transport-related social exclusion. J. Transp. Geogr. 15 (3), $151-160$.

Shannon, T., Giles-Corti, B., Pikora, T., Bulsara, M., Shilton, T., Bull, F., 2006. Active commuting in a university setting: assessing commuting habits and potential for modal change. Transp. Policy 13 (3), 240-253.

Soria-Lara, J.A., Valenzuela-Montes, L.M., Pinho, P., 2015. Using 'mobility environments' in practice: lessons from a metropolitan transit corridor in Spain. J. Environ. Plann. Policy Manage. 17 (5), 553-572.

Sperling, D., Gordon, D., 2009. Two Billion Cars: Driving Toward Sustainability. Oxford University Press.

Sterrett, K., Hackett, M., Hill, D., 2012. The social consequences of broken urban structures: a case study of Belfast. J. Transp. Geogr. 21 , 49-61.

Thøgersen, J., 2006. Understanding repetitive travel mode choices in a stable context: a panel study approach. Transp. Res. Part A: Policy Pract. 40 (8), $621-$ 638.

Tolley, R., 1996. Green campuses: cutting the environmental cost of commuting. J. Transp. Geogr. 4 (3), $213-217$.

Zhang, J., Yu, B., Chikaraishi, M., 2014. Interdependences between household residential and car ownership behavior: a life history analysis. J. Transp. Geogr. $34,165-174$.

Zhou, J., 2012. An analysis of university employee car-sharers in Los Angeles. Transp. Res. Part D: Transp. Environ. 17 (8), $588-591$. 